\title{
Delineating the structural, functional and evolutionary relationships of sucrose phosphate synthase gene family II in wheat and related grasses
}

\author{
Shailendra Sharma ${ }^{1,2,3^{*}}$, Nese Sreenivasulu ${ }^{1}$, Vokkaliga Thammegowda Harshavardhan ${ }^{1}$, Christiane Seiler ${ }^{1}$, \\ Shiveta Sharma ${ }^{4}$, Zaynali Nezhad Khalii ${ }^{1,5}$, Eduard Akhunov ${ }^{6}$, Sunish Kumar Sehgal ${ }^{6}$, Marion S Röder ${ }^{1}$
}

\begin{abstract}
Background: Sucrose phosphate synthase (SPS) is an important component of the plant sucrose biosynthesis pathway. In the monocotyledonous Poaceae, five SPS genes have been identified. Here we present a detailed analysis of the wheat SPSI/ family in wheat. A set of homoeologue-specific primers was developed in order to permit both the detection of sequence variation, and the dissection of the individual contribution of each homoeologue to the global expression of SPSII.

Results: The expression in bread wheat over the course of development of various sucrose biosynthesis genes monitored on an Affymetrix array showed that the SPS genes were regulated over time and space. SPSII homoeologue-specific assays were used to show that the three homoeologues contributed differentially to the global expression of SPSII. Genetic mapping placed the set of homoeoloci on the short arms of the homoeologous group 3 chromosomes. A resequencing of the A and B genome copies allowed the detection of four haplotypes at each locus. The 3B copy includes an unspliced intron. A comparison of the sequences of the wheat SPSII orthologues present in the diploid progenitors einkorn, goatgrass and Triticum speltoides, as well as in the more distantly related species barley, rice, sorghum and purple false brome demonstrated that intronic sequence was less well conserved than exonic. Comparative sequence and phylogenetic analysis of SPSII gene showed that false purple brome was more similar to Triticeae than to rice. Wheat - rice synteny was found to be perturbed at the SPS region.
\end{abstract}

Conclusion: The homoeologue-specific assays will be suitable to derive associations between SPS functionality and key phenotypic traits. The amplicon sequences derived from the homoeologue-specific primers are informative regarding the evolution of SPSII in a polyploid context.

\section{Background}

Sucrose plays an important role in the plant life cycle. As the major photosynthetic product, it is essential for growth, the synthesis of biomass and as a carbon and energy source. In the cereals, it is converted into starch and storage proteins, while many dicotyledonous species use it to form lipids and/or storage proteins $[1,2]$. Under stressful conditions (e.g, low temperature or drought),

\footnotetext{
* Correspondence: shail6_r@rediffmail.com
'Leibniz Institute of Plant Genetics and Crop Plant Research (IPK), Corrensstr.

* Correspondence: shail6_r@rediffmail.com
'Leibniz Institute of Plant Genetics and Crop Plant Research (IPK), Corrensstr. 3, D-06466 Gatersleben, Germany
}

(C) 2010 Sharma et al; licensee BioMed Central Ltd. This is an Open Access article distributed under the terms of the Creative Commons

the plant cell typically accumulates sucrose as a protective osomoticum [3,4]. Sucrose phosphate synthase (SPS) is one of the main regulatory enzymes involved in sucrose biosynthesis pathway in wheat and many other crop species [5]. It catalyzes the conversion of Fructose6-Phosphate and UDP-glucose into Sucrose-6-phosphate, which is subsequently hydrolysed to sucrose by the action of sucrose phosphate phosphatase (SPP).

In important crop plants like maize, rice and sugarcane, plant growth and productivity have been correlated with SPS activity. SPS activity has been correlated with sucrose accumulation in sugarcane stems [6-8], while in maize, 
correlations have been demonstarted with vigour and biomass yield $[9,10]$. Genetic studies in maize have also shown that grain yield QTL (quantitative trait loci) are linked to SPS activity QTL, as are ADP-glucose pyrophosphorylase (another starch biosynthesis enzyme) activity QTL [11-13]. In rice, the location of plant height QTL appears to coincide with that of OsSPS1, as the transgenic plants with increased SPS activity grew taller than the non-transformed control [14]. In tobaccco lines engineered to over-express SPS, UDP- glucose pyrophosphorylase and sucrose synthase, plant height was increased and flowering time delayed [15], while the heterologous expression of AtSPS induced longer stems and greater biomass [16]. Finally, the over-expression of ZmSPS in potato was shown to improve a number of yield-realted characters [17], while in tomato, it altered the pattern of carbohydrate partitioning in the leaf [18].

The regulation of SPS activity is rather complex, and involves fine tuning at both the transcriptional and the post-translational level [2]. Among the dicotyledonous plant species, three SPS gene families have been recognized, while in the monocotyledonous Poaceae species wheat, maize and rice, there are five gene families [5]. Here, we report the temporal patterns of expression of $S P S$ and SPP, and the discovery of structural polymorphisms between homoeologous copies of SPSII. We have also identified the presence of unspliced introns in one of its homoeologues. Evolutionary relationships among the SPSII homoeologues have been illustrated by comparisons between the gene sequences present in hexaploid wheat and its progenitors. Finally, we extend the phylogeny to other grass species.

\section{Results}

\section{Gene expression analysis of sucrose biosynthesis genes} during wheat plant ontogeny

As a first step, the wheat Affymetrix probe sets representing SPS and SPP members were identified, based on the criteria used to define the five SPS [5] and the three SPP [19] types. The expression patterns of these gene family members was extracted from the normalized expression data from imbibed embryo, coleoptile, seedling root, crown, seedling leaf, stem (at anthesis), developing anther, developing caryopsis (sampled at 3-5 dap, 8 dap, 18 dap and 22 dap), and the developing endosperm and embryo at 22 dap. Except for SPPIII, the SPP genes were expressed throughout plant development, although their level tended to be highest in the developing anther and developing caryopsis (Figure 1). Different SPS members show highly regulated spatio-temporal expression patterns during plant ontogeny, suggesting the existence of fine regulation at the first step of sucrose biosynthesis.

As SPSI was prominently expressed in the seedling leaf and the mature stem (Figure 1) its function may be associated with the re-synthesis of sucrose from fructan. SPSII (Ta.4256.1.S1_at), SPSIII (Ta.20568.1.S1_at), TaSP$S I V$ and TaSPSVa were prominently expressed during microsporogenesis (at premeiosis, throught meiosis and in immature pollen) and in the mature anther. All the SPP families were highly expressed during anther development (Figure 1). Thus, these genes are clearly important for normal pollen/anther development. Interestingly, note that in the Arabidopsis thaliana mutant kns2-1, an altered SPS glycosyltransferase I domain disrupts the function of sucrose synthesis, and this leads to changes in the synthesis of the pollen primexine or callose [20]. In the wild type, SPS5.2 (KNS2) is expressed in uni- and bicellular microspores as well in more mature anthers. The present data showed that probably all the SPS and SPP genes were constitutively expressed throughout caryopsis development, indicating that more than one SPS isoforms contributes to overall SPS activity (Figure 1).

Furthermore, it is important to know how these different SPS members are spatially expressed in different seed tissues and possible co-expression of these members in the same cell for making hetero-oligomeric complexes to be functional. The developing caryopsis imports sucrose to driving its growth and allow storage of metabolites. The expression of SPS and SPP members within the developing caryopsis suggests that sucrose cleavage, transport and re-synthesis during its internal transport can be differentially regulated within various distinct tissues. Of particular interest was the observation that both variants of SPSII are differentially expressed in the developing caryopsis. Thus, Ta.4256.1.S1_at was highly expressed both throughout anther development and during late embryo development, while TaAffx.8003.1.S1_at was expressed most strongly during early caryopsis development. The contribution of the individual SPSII homeologues and the occurance of alternative splicing are expanded upon in the following section. Besides alternative splicing, a contributory reason for the present exclusive focus on the SPSII family was that there were four SPSII cDNA sequences available in the public domain, which gave the opportunity to design homoeologue-specific primers for three wheat genomes. Insufficient sequence data are presently available for the other SPS families. Therefore, in order to study polyploidization and phylogenetics relationship between three wheat genomes, SPSII was selected as best suited candidate.

\section{Structural analysis of SPSII genes in wheat and its relatives}

Both introns and exons were targeted for the design of homoeologue-specific primers (Figure 2). The resulting amplicons allowed for the sequencing of portions of each of the SPSII homoeologues. In all, 7,364 bp of the 


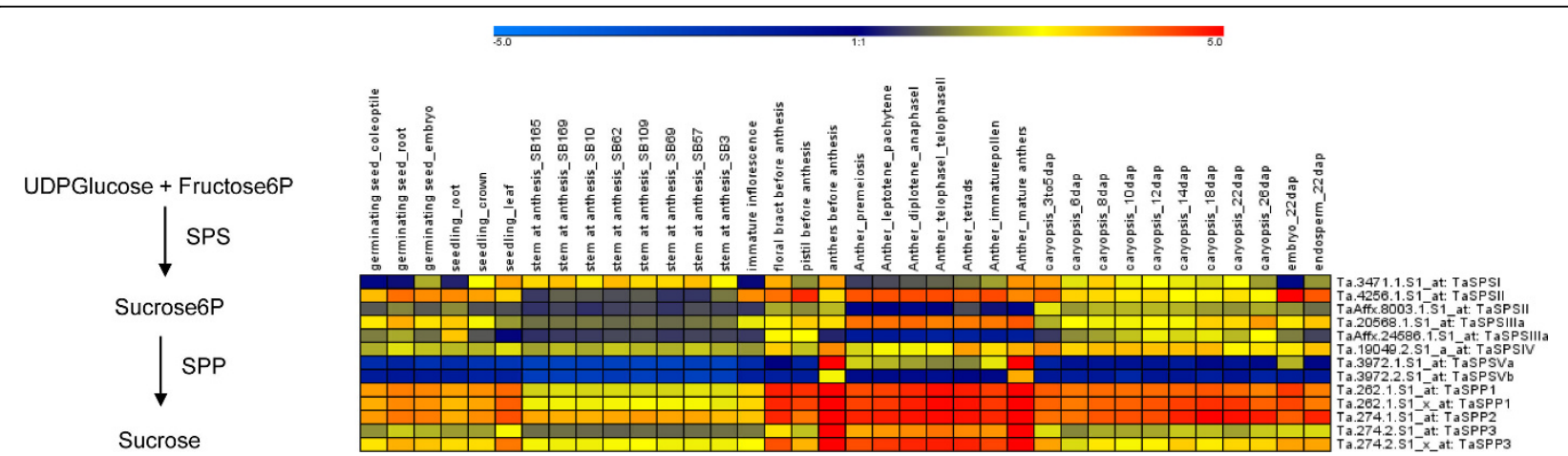

Figure 1 Spatial and temporal expression patterns of SPS and SPP during plant development. The expression values were calculated on a logarithmic scale (base 2). Red signal denotes high expression; yellow, moderate expression and blue, low expression. Affymetrix gene IDs are shown on the right panel, and the developmental stage sampled in vertical columns by the top panel.

cv. Chinese Spring A genome homoeologue sequence was acquired from a combination of homoeologue-specific amplicons and flow-sorted chromosome arm $3 \mathrm{~A}$ sequences (kindly provided by Dr. E. Akhunov). We acquired 3,883 bp of the $B$ genome homoeologue sequence, and 1,184 bp of the D genome homoeologue, both from cv. Chinese spring (Additional file 1). Sequence of the SPSII orthologues in Triticum urartu (einkorn wheat - genome AA; A genome progenitor), $T$. speltoides (genome $\mathrm{SS} \sim \mathrm{BB}$; putative $\mathrm{B}$ genome progenitor), Aegilops tauschii (goatgrass-D genome progenitor) and barley (genome $\mathrm{HH}$ ) was obtained in a similar fashion. Their alignment is provided as Additional file 2. SPSII has 12 introns and 13 exons in wheat, barley, rice, sorghum and purple false brome (Brachypodium distachyon) (Additional file 1, Figure 3). In rice, sorghum and purple false brome, the gene length is $12,838 \mathrm{bp}$, 12,456 bp and 8,492 bp, respectively (Additional file 1). In einkorn and T. speltoides six exons and six introns were amplified, while in goatgrass, this was extended to eight exons and seven introns. In hexaploid wheat, certain regions could not be sequenced either due to the presence of large introns or due to unavailability of homoeologue-specific primers. The intronic sequences were more polymorphic than the exonic ones, which were highly conserved among the species compared (Additional files 3, 4, 5, 6). In the six exons for which sequence was available, the level of similarity level ranged from $83.1 \%$ (between barley and sorghum) to $99 \%$ (between the wheat A genome homoeologue and einkorn) (Additional file 6b). In contrast, for the six intronic regions compared, the similarity level ranged from $35.5 \%$ (between purple false brome and sorghum) to 99\% (between the wheat A genome copy and that of einkorn) (Additional file 6c). Intron 12 of the wheat B genome homoeologue was unspliced, since it was present in the cDNA AF347066 [5]. Sequence alignment and subsequent cluster analysis showed that the purple

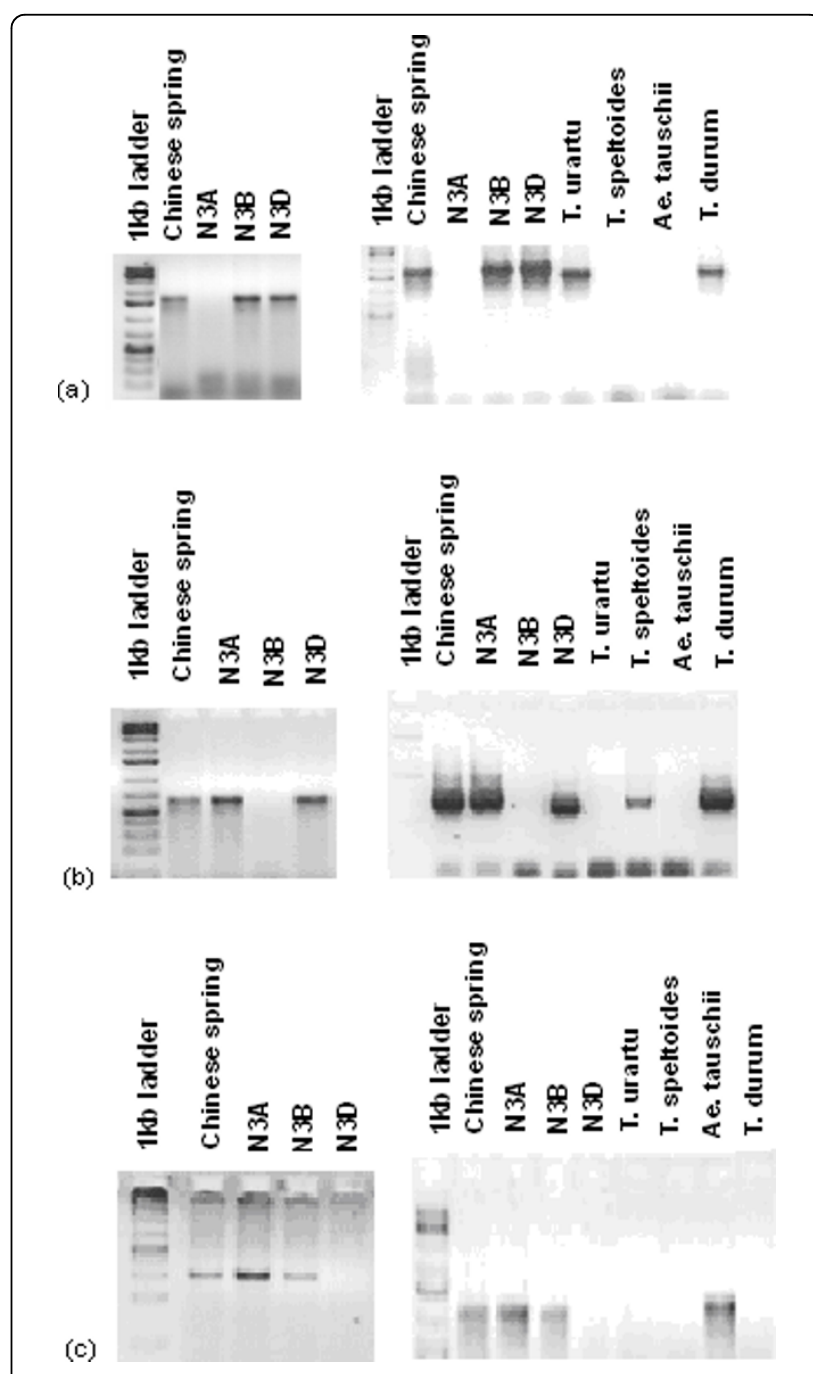

Figure 2 SPSSII homoeologue-specific primer driven PCR of cv. 'Chinese Spring', relevant nulli-tetrasomic lines and selected progenitor species. (a) A genome copy (primer pair w-spsll-dL \& w-spsll-24R), (b) B genome copy (primer pair w-spsll-65L \& w-spsll73R), (c) D genome copy (primer pair w-spsll-1DL \& ss-spsII-D11R). 


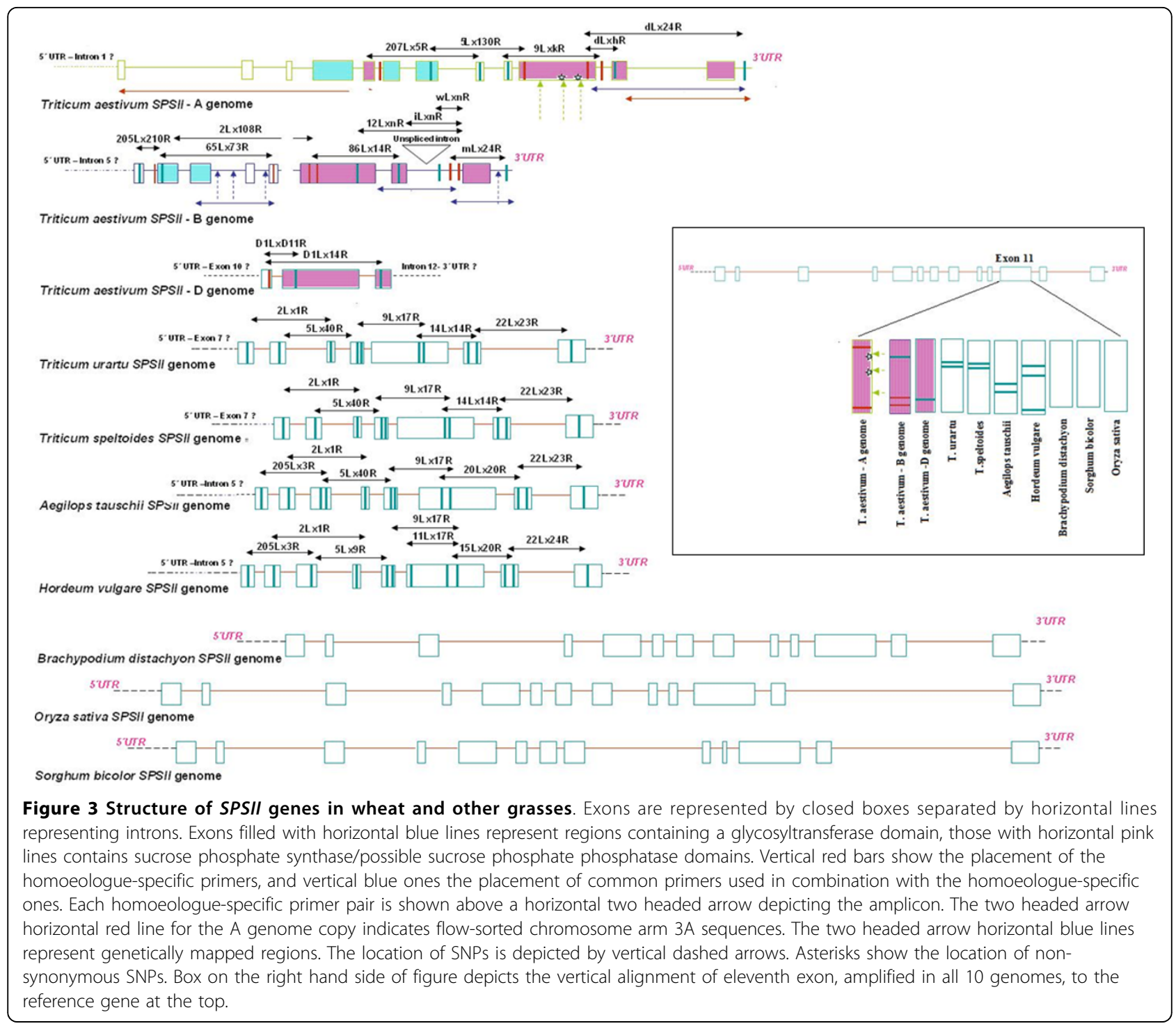

false brome sequence was more similar to those of wheat and barley in comparison to rice sequence, and the sorghum sequence was the one most highly diverged from that of wheat (Figure 4), as was the expectation on taxonomic grounds [21].

\section{Genetic mapping of TaSPSII genes in wheat}

The homoeologue-specific primers developed for each of the wheat SPSII copies were validated by an analysis of the nulli-tetrasomic lines of cv.'Chinese Spring'; this showed that each amplicon was derived from a member of the homoeologous group three chromosomes (Figure 2). A polymorphism for the A genome copy between the parents of the ITMI (International Triticeae Mapping Initiative) mapping population allowed it to be located $13.6 \mathrm{cM}$ distal of Xtam61a in the sub-telomeric of the short arm of chromosome 3A (Figure 5).
The B genome copy was placed in a matching location on chromosome 3B between Xksug53a and Xcdo460c (Figure 5). The D genome copy was not mappable in the ITMI mapping population, but was localised to D genome through anueploid stocks.

\section{Detection of SNP diversity}

The SPSII amplicons obtained from 27 diverse wheat accessions were sequenced in a search for single nucleotide polymorphisms (SNPs). For the A genome copy, the intron 6 to exon 12 region was targeted, while for the B genome, the target was exon 6 to the 3' UTR, and, for the D genome copy, intron 10 to exon 12. Three SNPs were uncovered in the 3A gene, all within an exonic region corresponding to the sucrose phosphate synthase/possible sucrose phosphate phosphatase domain. Of the three SNPs, two were 


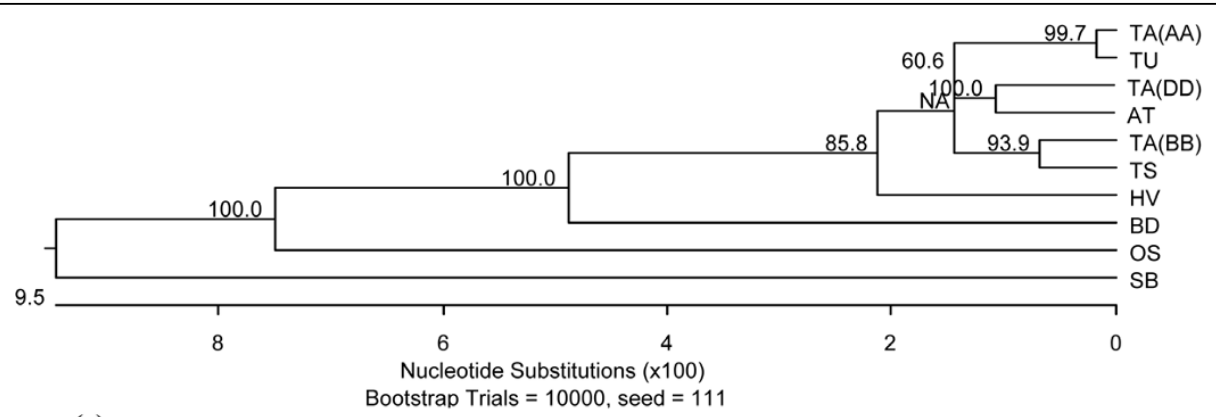

(a)

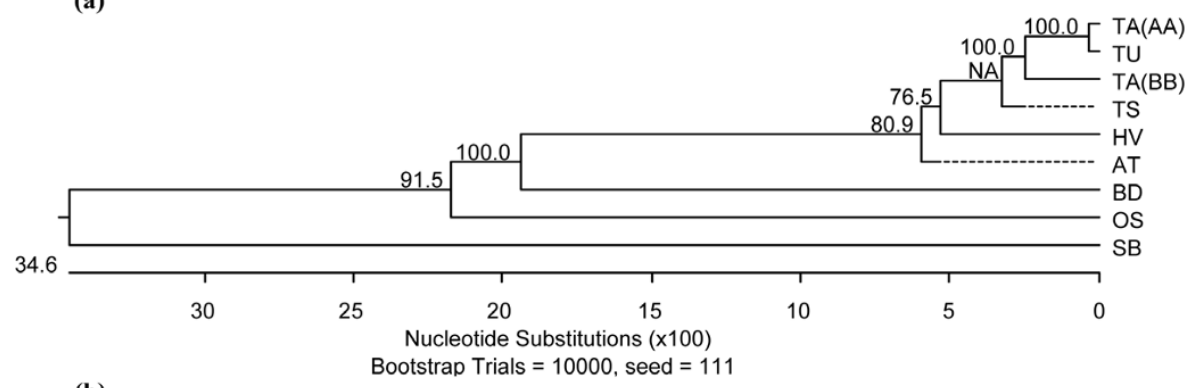

(b)

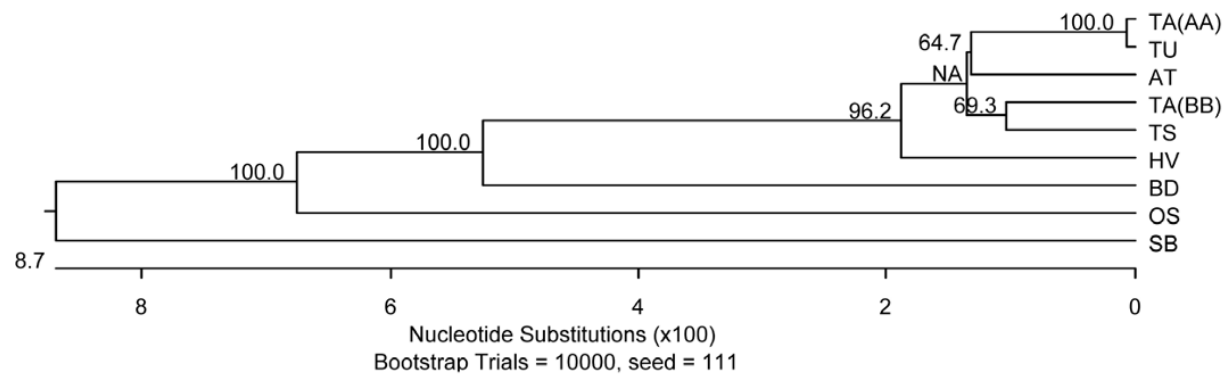

(c)

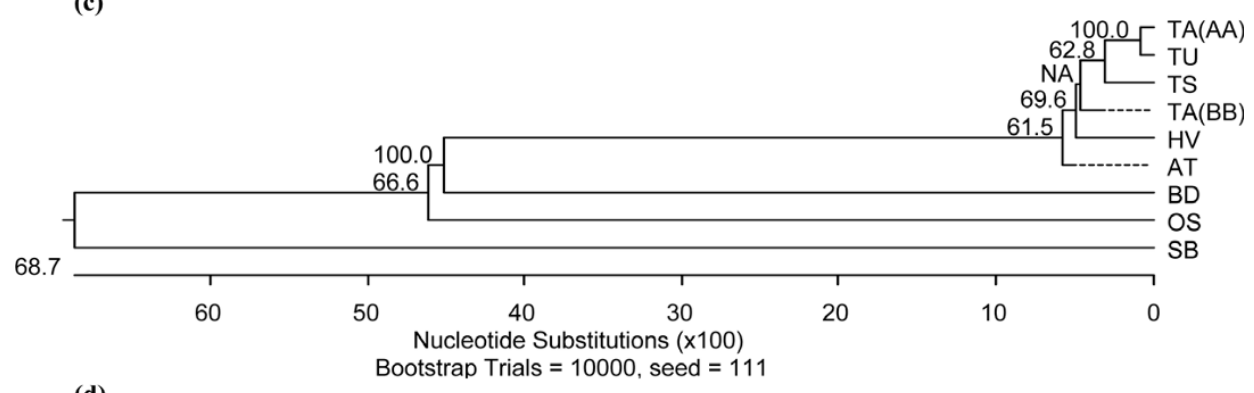

(d)

Figure 4 Phylogeny of SPSII. (a) A phylogenetic tree based on the alignment of SPSII sequences acquired from ten genomes (see also Fig. 4), (b) A phylogenetic tree based on the alignment of SPSII intron 7 to exon 13, based on nine genomes (see also Additional file 2), (c) A phylogenetic tree based on the alignment of SPSI/ exon 8 to exon 13 based on nine genomes (see also Additional file 3), (d) A phylogenetic tree based on the alignment of SPSII intron 7 to intron 12 based on nine genomes (See also Additional file 4). TA(AA): Triticum aestivum A genome, TA(BB): Triticum aestivum B genome, TA(DD): Triticum aestivum D genome, TU: Triticum urartu, TS: Triticum speltoides, AT: Aegilops tauschii, HV: Hordeum vulgare, OS: Oryza sativa, SB: Sorghum bicolor, BD: Brachypodium distachyon. Dashed lines indicate a negative branch length.

non-synonymous SNPs; the first induced the residue change argeneine ${ }^{1554}$ to lysine ${ }^{1554}$, and the second from alanine ${ }^{1599}$ to valine ${ }^{1599}$ (Figure 3, Table 1). Of the four B genome copy SNPs detected, three were located within intronic sequences, and one within the 3' UTR (Figure 3, Table 1). No SNP was detected within the $\mathrm{D}$ genome copy. Overall, it was possible to define four distinct haplotypes for each of the A and the $\mathrm{B}$ genome copies (Table 1 ).

\section{Three genomes differentially contributes to the expression of TaSPSII}

Quantitative real time PCR based on exonic sequences of the A and D genome copies, and within the unspliced 


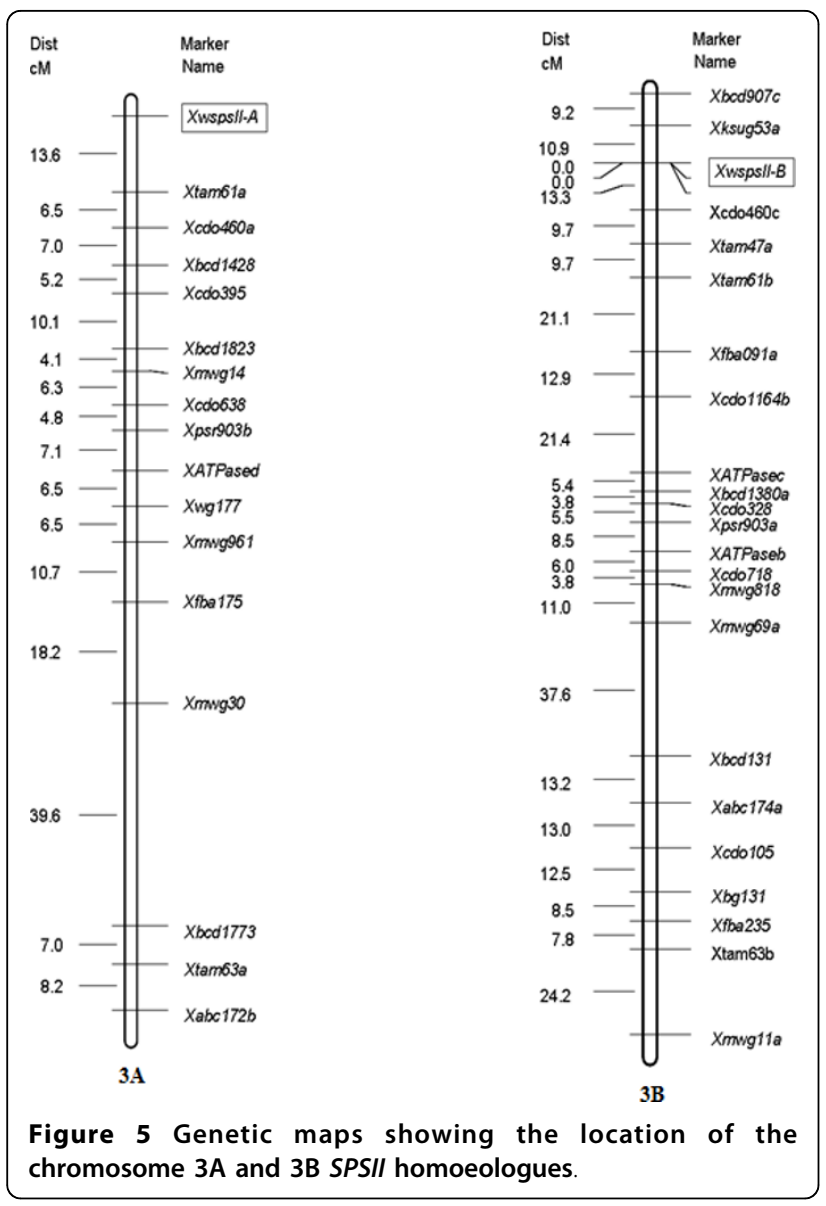

intronic region of the $B$ genome copy was applied to various tissues of, cv 'Prinz'. SPSII was expressed during germination as well as in the developing caryopsis at four and eight days after anthesis (DAF). A similar level of expression was measured in the germinating seed and in the developing caryopsis at four DAF, and this fell somewhat by eight DAF. The A genome copy dominated the global expression of SPSII; there was very little contribution from the B genome copy (Figure 6).

\section{Discussion}

\section{Genomic sequence analysis of SPSII genes}

Sequence variation in sucrose biosynthesis pathway genes such as SPS is of particular interest because its consequence can be a change at the level of phenotype, sometimes involving vigour, biomass productivity and economic yield. Markers from the expressed portion of genome, that are responsible for some important physiological aspects, have been developed in wheat [22-26]. A particular complication in bread wheat is that most genes which are present in single copy in the diploid grasses such as rice and purple false brome are represented by three copies. In order to interpret wheat gene expression data, it is therefore necessary to derive specific assays for each homoeologous copy, as we have described here for SPSII (Table 2). These assays are also necessary for the application of pyrosequencing as a SNP discovery platform $[27,8]$.

\section{Frequency of SNPs}

The low level of SNP within SPSII suggests that variation in its sequence is constrained by selection against changes in its physiological activity. Other starch metabolism enzyme encoding genes have similarly been associated with little sequence variation [22,28]. The observed SNP frequency was 1 per 797 bp within the A genome copy, and 1 per 916 bp within the B genome copy, frequencies which are typical for bread wheat [29-31]. Most of the SPSII SNPs were located within either an intron or the 3' UTR, with only two exonic non-synonymous ones uncovered. These latter substitutions may be of physiological significance, given that an alanine to valine change compromised the processing of a $22 \mathrm{kDa}$ protein in maize [32], and that an arginine to lysine substitution in the bZIP domain of the maize opaque gene abolished the specificity of its DNA binding [33].

\section{Presence of an unspliced intron in TaSPSII CDNA is mapped to $B$ genome}

Intronic sequence was relatively variable at the interspecific and inter-generic level (Additional files 4, 5c),

Table 1 Haplotypes for SPSII gene obtained in wheat A and B genomes

\begin{tabular}{|c|c|c|c|c|c|c|c|c|c|c|}
\hline $\begin{array}{l}\text { Haplotypes } \\
\text {-A Genome }\end{array}$ & $\begin{array}{l}\text { SNP1 } \\
\text { (Exonic, } \\
1432 \text { bp }\end{array}$ & $\begin{array}{l}\text { SNP2* } \\
\text { Exonic, } \\
1554 \mathrm{bp})\end{array}$ & $\begin{array}{l}\text { SNP3* } \\
\text { (Exonic, } \\
1599 \text { bp) }\end{array}$ & $\begin{array}{l}\text { Cultivars } \\
\text { per } \\
\text { haplotype }\end{array}$ & $\begin{array}{l}\text { Haplotypes- } \\
\text { B genome }\end{array}$ & $\begin{array}{l}\text { SNP1 } \\
\text { (Intronic, } \\
451 \mathrm{bp} \text { ) }\end{array}$ & $\begin{array}{l}\text { SNP2 } \\
\text { (Intronic, } \\
523 \text { bp) }\end{array}$ & $\begin{array}{l}\text { SNP3, } \\
\text { (Intronic } \\
793 \text { bp) }\end{array}$ & $\begin{array}{l}\text { SNP4 } \\
\text { (3'UTR) }\end{array}$ & $\begin{array}{l}\text { Cultivars } \\
\text { per } \\
\text { haplotype }\end{array}$ \\
\hline SPShap1 & C & $G(A R G)$ & $C(A L A)$ & 10 & SPShap1 & $A$ & $\mathrm{~T}$ & G & C & 15 \\
\hline SPShap2 & $\mathrm{T}$ & $G(A R G)$ & $\mathrm{T}(\mathrm{VAL})$ & 9 & SPShap2 & G & $\mathrm{T}$ & A & G & 3 \\
\hline spshap3 & $\mathrm{T}$ & $G(A R G)$ & $C(A L A)$ & 6 & sPShap3 & G & $\mathrm{T}$ & G & G & 6 \\
\hline \multirow[t]{2}{*}{ SPShap4 } & C & A (LYS) & $C(A L A)$ & 2 & SPShap4 & G & C & G & G & 3 \\
\hline & & & & Total $=27$ & & & & & & Total $=27$ \\
\hline
\end{tabular}

Note: Position of the SNPs are based on sequence alignment (supplementary Figure 1). Asterisk showed the location location of non synonymous SNPs. 


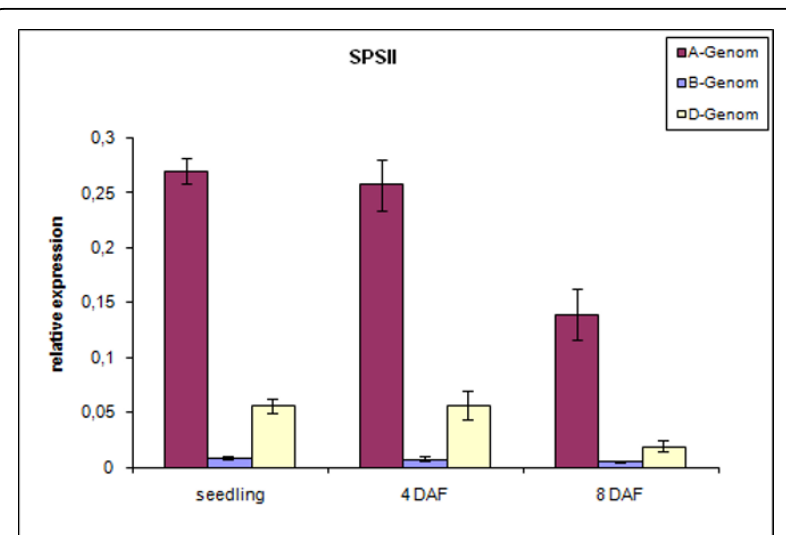

Figure 6 Relative expression levels of SPSII homoeologues in cv 'Prinz'. Relative expression levels of SPSII shown are based on delta Ct calculation. To compare data from different PCR runs or cDNA samples, $C_{T}$ values for all genes were normalized to the $C_{T}$ value of the housekeeping gene (serine/threonine protein phosphatase, TaPP2A) included in each PCR run. The expression level of each gene of interest $(\mathrm{GOI})$ is presented as $2^{-\Delta C T}$, where $\Delta C_{T}=C_{T G O I}-C_{\text {TREF. }}$. Mean values were assessed from three biological replicates for seedling materials and caryopses sampled four days after anthesis, and from two replicates for caryopses sampled eight days after anthesis. Error bars indicate standard deviations from the mean.

while exonic sequence was well conserved (Additional files $3,5 \mathrm{a}$ and $5 \mathrm{~b}$ ). This pattern is characteristic of gene sequences in the grasses [21,34]. Analysis of the sequence of SPSII cDNA clone AF347066 has demonstrated alternative splicing for one of the SPSII genes [5]. The development of homoeologue-specific assays has allowed the unspliced intron to be located to the $\mathrm{B}$ genome copy of SPSII. Both of the alternative transcripts (spliced and unspliced) occurred in the pre anthesis spike [5]. cDNA of einkorn wheat (genome AA), goatgrass (genome DD), durum wheat (T. durum, genome constitution $\mathrm{AABB}$ ) and bread wheat (genome AABBDD) were amplified using primer pairs w-spsII-iL \& w-spsII-nR, which target the unspliced intron in the B genome copy of SPSII. Amplification was observed from bread and durum wheat template, but not from either einkorn or goatgrass (Figure 7b). An aneuploid analysis confirmed the $B$ genome specificity of the unspliced intron (Figure 7c). Thus the unspliced intron is clearly restricted to the B genome copy of SPSII.

\section{Contribution of $A$ and $D$ genome for the expression of TaSPSII}

All five SPS members appeared to be both spatially and temporally regulated. Of special interest in SPSII with two different variants, Ta.4256.1.S1_at: highly expressed throughout anther development as well also during late seed development in embryo and TaAffx.8003.1.S1_at: expressed mainly during early seed development. The expression pattern of Ta.4256.1.S1_at was consistent with that previously exposed by Northern blot analysis [5], but the expression of the latter gene has not been documented before. Although microarray-based expression data reflect very clearly any differences between distinct genes, they are not informative at the level of homoeologues, because the array features are not homoeologue-specific. In this case, homoeologue specific primers could play a vital role in knowing the contribution of three different genomes in terms of gene expression pattern. Similar strategy was also used earlier for studying expression patterns of benzoxazinones biosynthesis in wheat contributed by different genomes [35]. The present data have shown that the A genome copy of SPSII dominated the global expression of SPSII and that the B genome copy - despite its two alternative transcripts - the least.

\section{Synteny to rice is perturbed at SPSII locus}

At the cDNA sequence level, SPSII is highly similar to its rice orthologue, which is located on chromosome 8 [5]. Gene order is largely conserved among the major cereal genomes [36-38], which has allowed for the identification of a syntenic relationship between rice chromosome 8 and the wheat chromosomes of homoeologous group seven. The prediction is therefore that wheat SPSII should map to wheat chromosomes 7A, 7B and $7 \mathrm{D}$, and not, as is the case, to chromosomes $3 \mathrm{~A}, 3 \mathrm{~B}$ and 3D. The chromosomal location that we have deduced is secure, as it relies on a combination of anaeuploid analysis, genetic mapping, the placement of SPSII ESTs http://wheat.pw.usda.gov/cgi-bin/westsql/map_locus.cgi, and the presence of SPSII sequence on flowsorted chromosome 3A template. Rice chromosome 1 has been reported to be highly syntenic to wheat chromosome three $[38,39]$. In the present study, it appears that a segment at least of the group 3 chromosomes has lost synteny with rice chromosome 1 . Failure of synteny and breakdown of colinearity is well documented $[24,38,40,41]$. Prominent examples involve the regions around both GBSS1 [42] and the Pbf orthologues in wheat and barley [24]. Of 537 mapped ESTs mapping to the wheat group 3 chromosomes, $15 \%$ shared homology with rice genes mapping outside of chromosome 1 , and various complexities associated within co-linear regions suggests that the relationship between these chromosomes is not straightforward [38]. Similarly, the analysis of $1 \mathrm{~Gb}$ of chromosome $3 \mathrm{~B}$ has identified the presence of gene sequences whose rice orthologues do not map to chromosome 1 [43], while the annotation of $17 \mathrm{Mb}$ of various regions of chromosome 3B has shown that only half of the predicted genes present had orthologues on rice chromosome 1 [44]. The SPSII genes lie in the distal region of their respective wheat chromosome, which suggests that co-linearity with rice may be 
Table 2 Primer sequences used for the amplification of SPSII gene in wheat and other related grasses

\begin{tabular}{|c|c|c|}
\hline Forward primer $\left(5^{\prime}-3^{\prime}\right)$ & Reverseprimer $\left(5^{\prime}-3^{\prime}\right)$ & PCR profile \\
\hline A. Triticum aestivum- A genome & & 1 \\
\hline 1. w-spsIl-207L* (CGTITATCCCCCCATAAGAGA) & w-spsll-5R (CCCAAATGGTTCAATATAAGCACA) & \\
\hline 2. w-spsIl-5L (AGCACAAATGGAGCTGTTTTG) & w-spsll-130R* (AATATCCCTCAAAGAGTCACCAC) & \\
\hline 3. w-spsII-9L (GCTTATGGTCTACCTATGGTTGCT) & w-spsIl-kR* (ATAGTAGGGAAGGTTGAGAAAATCA) & \\
\hline $4^{\#}$. w-spsII-dL* (AGAAAAGAATAGCGAGAGTGGAA) & w-spsII-24R (AGATGCTAATTATTCGTAGAGATGCAT) & \\
\hline $5^{a} \cdot$ w-spsIl-dL (AGAAAAGAATAGCGAGAGTGGAA) & w-spsll-hR (ATGCTTGAATTCTCATTGTCTTC) & \\
\hline B. Triticum aestivum -B genome & & 1 \\
\hline 1. w-spsIl-205L (AGCTGCTACGGTCGTGAAATG) & w-spsll-210R* (CTCTTATGGGGGGATAAAAAT) & \\
\hline 2\#. w-spsil-65L (CATTTGGTGAACACCATGAGCTA) & w-spsil-73R* ( CCGGTGTATATCGACAGGT) & \\
\hline 3. w-spsIl-2L (GCTGGTTAAGGCATTTGGT) & w-spsIl-108R* (AACTCCTTCCATATTTCGACATGT) & \\
\hline 4. w-spsII-86L* (GAAAAATCAGGCAACATGTCG) & w-spll-14R (TGCTTGGGATCGTGATGCT) & \\
\hline 5. w-spsIl-iL (CACTAAGGTTTGGTTATTCCTATAACTGT) & w-spsll-nR * (CCTGCACAAAGATGAACAAACG) & \\
\hline 6\#. w-spsil-mL* (AACCACAAAGTCCTGATGGTACG) & w-spsII-24R (AGATGCTAATTATTCGTAGAGATGCAT) & \\
\hline $7^{\#}$. w-spsll-12L (AAACTATTTGTCACGGGTTGGT) & w-spsll-nR (CCTGCACAAAGATGAACAAACG) & \\
\hline $8^{\mathrm{a}}$. w-spsIl-wL (GTCGTTTGACACCTCATTGTTG) & w-spsil-nR (CCTGCACAAAGATGAACAAACG) & \\
\hline C. Triticum aestivum -D genome & & 2 \\
\hline 1 w-spsII-D1L* (CCAAAATGGTGGGCCTGTTG) & W-spsll-14R (TGCTTGGGATCGTGATGCT) & \\
\hline $2^{a}$. w-spsIl-D1L (CCAAAATGGTGGGCCTGTTG) & w-spsII-D11R GAAACTTCAGTAGCATCATCACTCTTTG) & \\
\hline D. Triticum urartu, Triticum speltoides, Aegilops tauschii, Hordeum vulgare & & 1 \\
\hline 1. W-spsIl-205L (AGCTGCTACGGTCGTGAAATG) & w-spsIl-3R (TGGAACTTCAGATTGCTTATGG) & \\
\hline 2. w-spsil-2L (GCTGGTTAAGGCATTTGT) & w-spsIl-1R (GGTGAGCCCAAATGGTTCAATATA) & \\
\hline 3. W-spsIl-5L (AGCACAAATGGAGCTGTTTG) & w-spsll-40R (CCCGGTGTATATCGACAGGC) & \\
\hline 4. w-spsIl-9L (GCTTATGGTCTACCTATGGTTGCT) & w-spsIl-17R (GATGTTGACAATACAAAACCAAGAGC) & \\
\hline 5. w-spsII-22L (TTCATACCTGTTCTAGCATCACGA) & w-spsll-23R (GGAACCTATGAACAATTTCACCA) & \\
\hline 6. W-spsIl-14L (GAGCAGCATCAGAGATACATCCTT) & w-spsIl-14R (TGCTTGGGATCGTGATGCT) & \\
\hline 7. w-spsII-20L (AAAGCTGGGGCCACCAC) & w-spsll-20R (TCGTGATGCTAGAACAGGTATGAA) & \\
\hline 8. w-spsII-22L (TTCATACCTGTTCTAGCATCACGA) & w-spsll-24R (AGATGCTAATTATTCGTAGAGATGCAT) & \\
\hline 9. w-spsil-22L (TTCATACCTGTTCTAGCATCACGA) & w-spsll-31R (ACCGTCATGTTCGACAGCTCTAC) & \\
\hline 10. w-spsIl-11L (AATCAAAATGATATAGCTGAGGCACTT) & w-spsll-17R (GATGTTGACAATACAAAACCAAGAGC) & \\
\hline 11. w-spsIl-15L (GTTAACATCTGGGGGCATAGAAAT) & w-spsll-20R (TCGTGATGCTAGAACAGGTATGAA) & \\
\hline 12. w-spsIl-5L (AGCACAAATGGAGCTGTTTTG) & w-spsIl-9R (CACCATTTGGGTAGCAACC) & \\
\hline
\end{tabular}

${ }^{*}$ represents homoeologue-specific primers ; ${ }^{a}$ represents primer pairs used for quantitative real time PCR; ${ }^{*}$ represents primer pairs used for genetic mapping. For details of PCR profile please see methods section

lost there. Complex duplications, rearrangements and polyploidization events have led to the erosion of synteny and colinearity between rice and wheat [45-47]. The imminent completion of the sequence of the entire chromosome $3 \mathrm{~B}$ will allow the formulation of a better picture of orthologous relationships between wheat, rice, sorghum and false purple brome, as the genomes of later three species have already been fully sequenced.

\section{Phylogenetic relationship of TaSPSII in the context of polyploidization among hexaploid wheat and its progeniotors}

The sequence alignments and subsequent phylogenetic analyses was carried out considered either exons or introns or both (Figure 4, Additional files 2, 3, 4, 5, 6). The hexaploid wheat A genome copy consistently appeared closest to that of einkorn wheat, the A genome progenitor. At the level of exons only, the B genome copy appeared closely related to that of $T$. speltoides, a species considered to be taxonomically close to the $\mathrm{B}$ genome progenitor. Branching patterm in dendrogram was little disturbed when considered only introns depicting nonconserved nature of introns. With respect to the D genome copy, the comparison with its goatgrass orthologue was only possible on the basis of the sequence of one large exon. This showed that the D genome copy was more similar to the goatgrass orthologue than to any of the others. The level of homology in the exonic sequence between the A genome and the einkorn copy was $99.9 \%$, decreasing to $99.0 \%$ when intronic sequences were compared (Additional file 6). The equivalent similarities between the $B$ genome and the T. speltoides copies were $97.9 \%$ and $95.1 \%$ (Additional file 6). and that between the D genome and the goatgrass exonic sequence was $98.0 \%$. Thus, polyploidization has left exonic sequence largely unchanged, while intronic sequence has been able to drift somewhat, as has been 


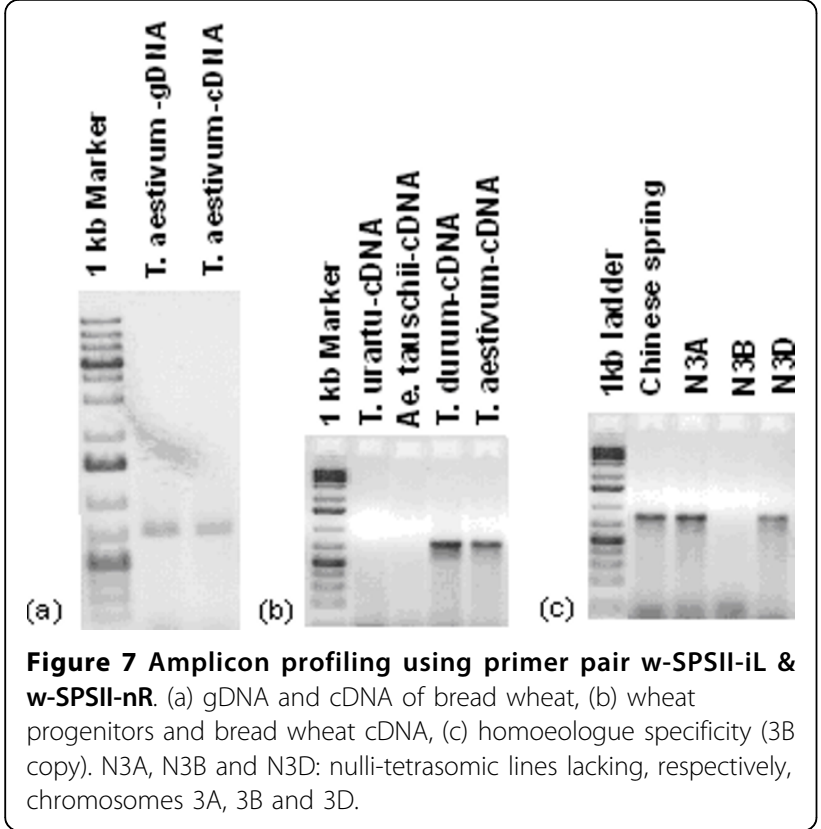

repeatedly observed in such comparisons [22,34]. The origin of bread wheat has involved two separate allopolyploidization events, the first between einkorn and a species closely related to $T$. speltoides, and the second between the resulting wild tetraploid $T$. dicoccoides and goatgrass [48]. The phylogeny predicted from the sequences of the SPSI homoeologues and wild species orthologues is fully consistent with this settled origin (Figure 4) and supports the previous published studies $[49,50]$.

\section{Phylogenetic relationship of TaSPSII between different grasses}

The phylogenetic analysis showed that the purple false brome SPSII sequence is more similar to those of wheat and barley than to that of rice, not only in terms of the sequence itself, but in terms of the gene's overall length. The purple false brome SPSII fragment extending from exon 8 to the 3'end of the gene (a region available for nine of the ten sequences) was 518 bp longer than the longest wheat or barley sequence, while this difference was $3,199 \mathrm{bp}$ in rice and 3,663 bp in sorghum. A number of phylogenetic studies have shown that the taxonomic separation between the Triticeae and purple false brome is much less than between them and rice [51-53], which is the reason why purple false brome has been so readily adopted as a model genome for the Triticeae [53-55].

\section{Conclusion}

A study of the expression of sucrose biosynthesis gene family members has revealed that SPS genes are highly regulated both spatially and temporally. We have been able to locate the SPSII homoeoloci to the short arms of their respective group 3 chromosomes, and have shown that their divergence is consistent with the known evolutionary relationships between the component genomes of hexaploid wheat. A phylogenetic study confirmed that purple false brome is a more appropriate model for the Triticeae than rice. We have provided evidence that the syntenic relationship between rice chromosome 8 and wheat group 3 chromosomes is perturbed in the region where the SPSII genes map. We have shown that the transcript of the B genome copy of SPSII exists as two alternative forms, one with, and the other without an intron. The $\mathrm{B}$ genome copy contributed least to the global expression of SPSII expression. The development of homoeologuespecific markers for, and SNPs within the wheat SPSII genes will enable the definition of any associations between SPSII genotype and plant phenotype in terms of vigour, biomass productivity or source-sink relationships.

\section{Methods}

\section{Plant materials and DNA isolation}

Seed stocks of 27 bread wheat accessions and representative progenitors species were obtained from the gene bank of the Leibniz Institute of Plant Genetics and Crop Plant Research, Gatersleben (Table 3). A set of 21 nullitetrasomic lines in cv. 'chinese spring' originally obtained from late Dr. E.R. Sears, Coloumbia, MO, was used for chromosome arm assignment of PCR products. Total genomic DNA was extracted from 4-6 g young leaf material as described earlier [56] to be used as a template for PCR amplification.

\section{Expression analysis of SPS and SPP members}

ESTs/cDNAs sequences for each of the five SPS gene families and three different SPP gene families in wheat were blasted against the probesets available on the wheat $61 \mathrm{~K}$ microarray platform on which corresponding wheat SPSI to SPSV and SPP1 to SPP3 cDNA gene sequences were identified with a significant e value of $10^{-10}$ or higher. To assess gene expression patterns of SPS and SPP gene family members during wheat plant development we downloaded CEL files of Affymetrix chip from the publicly available reference experiments (Series GSE12508; GSE9767; GSE6027) covering various tissues during germination (coleoptile, root, embryo), seedling stage (crown, leaf), stem at anthesis, reproductive tissues (immature inflorescence, floral bracts, pistil, mature anthers), various developmental stages of microsporogenesis and seed development. The transcriptome data of $61 \mathrm{~K}$ genes was subjected to RMA normalization with linear model using limma package. The log2 expression values were derived, differential expression is calculated with $\mathrm{P}$ value correction mode of Benzamini Hochberg and heat maps were generated for the differentially expressed SPS and SPP gene family members 
Table 3 Details of wheat accessions used for sequencing

\begin{tabular}{|c|c|c|}
\hline S. No. & Accessions & Country of origin \\
\hline 1 & Thatcher (TRI 1308) & USA \\
\hline 2 & Maris Huntsman (TRI 10287) & UK \\
\hline 3 & TRI 5714 & Iran \\
\hline 4 & TRI 5869 & Iran \\
\hline 5 & TRI 8392 & Mongolia \\
\hline 6 & TRI 9352 & Bulgaria \\
\hline 7 & TRI 16330 & Ethopia \\
\hline 8 & TRI 10470 & Afghanistan \\
\hline 9 & TRI 8161 & Egypt \\
\hline 10 & Chinese spring (TRI 23666) & China \\
\hline 11 & W7984 (mapping parent) & - (synthetic line) \\
\hline 12 & Prinz & Germany \\
\hline 13 & TRI 2419 & Tibet \\
\hline 14 & TRI 2425 & Tibet \\
\hline 15 & TRI 8373 & Syria \\
\hline 16 & TRI 8392 & Mongolia \\
\hline 17 & TRI 10330 & Kazakhstan \\
\hline 18 & TRI 10495 & Afghanistan \\
\hline 19 & TRI 10866 & Nepal \\
\hline 20 & TRI 1664 & Greece \\
\hline 21 & TRI 1706 & Albania \\
\hline 22 & TRI 1766 & Albania \\
\hline 23 & TRI 1772 & Greece \\
\hline 24 & TRI 2421 & Tibet \\
\hline 25 & TRI 11528 & Iraq \\
\hline 26 & TRI 11571 & Pakistan \\
\hline 27 & TRI 1624 & Peloponnesia \\
\hline 28 & Triticum urartu (AA) (TRI 17140) & Lebanon \\
\hline 29 & Aegilops speltoides (SS BB) (AE 413 ) & Israel \\
\hline 30 & Aegilops tauschii (DD) (TRI 145/96) & Azerbaijan \\
\hline 31 & Triticum dicoccoides (AABB) (TRI 18495) & Israel \\
\hline 32 & Triticum durum (AABB) (TRI 19197) & Turkey \\
\hline
\end{tabular}

covering the complete wheat plant ontogeny using Genesis software [57].

The designing of SPSII family specific primers and subsequent $P C R$ and cloning

The cDNA sequences of each SPS gene was retrieved from GenBank (accessions AF347064, AF347065, AF347066, AF347067, AF347068, AF347069, AF354298, AF534907 and AY4257109) and aligned using the Multalin [58] program. The SPSII gene family is represented by AF347064, AF347065, AF347066 and AF354298. Stretches of sequences limited to a particular gene family formed the basis for designing family specific primers, and in particular for SPSII (Table 2). To test the specificity of these family specific primers, the sequence of the resulting amplicons was used as a BLAST query against the GenBank sequence database http://blast.ncbi. nlm.nih.gov/Blast, applying high stringent conditions.
Template DNA for the subsequent PCR was represented by cvs. 'Chinese Spring', 'M6' (a synthetic hexaploid wheat) and 'Opata'. Each $25 \mu \mathrm{l}$ PCR comprised 50-100 ng template, $2.5 \mu \mathrm{l}$ of buffer containing $1.5 \mathrm{mM} \mathrm{MgCl} 2$, $0.2 \mathrm{mM} \mathrm{dNTP}, 10 \mu \mathrm{M}$ of each primer and $1 \mathrm{U}$ Taq polymerase. The amplification conditions consisted of an initial denaturation step $\left(94^{\circ} \mathrm{C} / 4 \mathrm{~min}\right)$, followed by four cycles of $94^{\circ} \mathrm{C} / 1 \mathrm{~min}, \mathrm{Ta} / 1 \mathrm{~min}, 72^{\circ} \mathrm{C} / 2 \mathrm{~min}$ (where Ta began at $62^{\circ} \mathrm{C}$ and was reduced by $1^{\circ} \mathrm{C}$ per cycle), then 30 cycles of $94^{\circ} \mathrm{C} / 1 \mathrm{~min}, 58^{\circ} \mathrm{C} / 1 \mathrm{~min}, 72^{\circ} \mathrm{C} / 2 \mathrm{~min}$ and completed by a final extension step of $72^{\circ} \mathrm{C} / 5 \mathrm{~min}$. This profile is referred to as "PCR profile 1". Amplicons were cloned into the pDrive cloning vector (QIAGEN, Hilden Germany). Plasmids were recovered from 20 clones from each of the three donor varieties using the QIAGEN plasmid purification kit (QIAGEN, Hilden Germany), and these were subjected to sequencing from both ends using a BigDye terminator v3.1 ready reaction cycle sequencing kit in combination with an ABI3730x1 sequencer (Applied Biosystems).

\section{Phred-Phrap-Consed analysis of sequenced clones}

Phred-Phrap-Consed analysis http://www.phrap.org/ phredphrapconsed.html was applied to ensure the quality of the sequences taken forward $[59,60]$. SNPs were detected by polyPhred [61] and visual inspection of Phrap assemblies. Two high quality contigs, assumed to represent two of the predicted three wheat homoeologues, were aligned using Sequencher software (Gene Codes Corporation, Ann Arbor, Michigan), and their consensus sequence formed a megablast $[62,63]$ query against the GenBank database. The outcome of this search was a confirmation that these two sequences were homologous to SPSII and not to any of the other SPS genes. Primer walking was employed to extend the sequence in both directions beyond the cloned region, and the sequence thereby acquired was subjected to megablast to ensure that it was SPSII specific.

\section{Gene annotation, designing of homoeologue-specific primers, sequencing}

A provisional gene structure was obtained by aligning the cDNA sequences with the rice genome sequence, and this was later confirmed by direct alignment with wheat genomic sequence. These alignments was performed using Genseqer http://www.plantgdb.org/ PlantGDB-cgi/GeneSeqer/PlantGDBgs.cgi software, applying the the rice specific splice site model and a high stringency [64]. Exon anchored primers were designed to span one or more intron using Primer3 software [65]. Homoeologue-specific primers targeted indels and/or base substitutions mainly in the intronic sequence (Table 2), and their specificity was tested by the amplification of DNA from nulli-tetrasomic 
template. Four primer pairs specific for the 3A copy of SPSII were obtained, and six for the 3B copy (Table 2, Figure 2). However, no 3D copy primers were identified in this way. To obtain an assay for the 3D copy, primers designed to amplify an exonic fragment from bread wheat were applied to the goatgrass accession TRI 145/ 96, and a region of this amplicon which was specific to goatgrass (839-880 bp, see Additional file 3) was then targeted for successful primer design (Table 2, Figure 2). The A and B genome copies were amplified using PCR profile 1 , while this was modified for the $\mathrm{D}$ genome copy to an initial denaturation step $\left(94^{\circ} \mathrm{C} / 4 \mathrm{~min}\right)$, followed by 35 cycles of $94^{\circ} \mathrm{C} / 1 \mathrm{~min}, 65^{\circ} \mathrm{C} / 1 \mathrm{~min}, 72^{\circ} \mathrm{C} / 2$ min and completed by a final extension step of $72^{\circ} \mathrm{C} / 5$ min (PCR profile 2). The primer sets were applied to obtain orthologous sequence from einkorn, T. speltoides, goatgrass and barley. For einkorn and $T$. speltoides it was possible to derive the sequence from intron 7 to the 3 'end of the gene in this way, and from goatgrass and barley from exon 6 to the 3'end of the gene. For rice, sorghum and false purple brome, sequence information was retrieved from, respectively, TIGR http://rice.plantbiology.msu.edu/, Phytozome http://www.phytozome.net and BrachyBase http://www.brachypodium.org/. All sequences are shown in Additional file 1, and have been deposited in GenBank as accession numbers GU797178, GU797179, GU797180, GU797181, GU797182, GU797183 and GU929217.

\section{Mapping of homeologue specific amplicons}

Homeologue specific markers showing polymorphism between parents of International Triticeae Map ping Initiative (ITMI) population were used for genetic mapping. For genetic mapping 112 recombinant inbred (RI) lines from the ITMI population were used. This population was derived from the cross between W-7984, an amphi hexaploid wheat and Mexican wheat variety Opata 85 from CIMMYT (Centro Internacional de Me joramiento de Maizy Trigo) [66]. The SPSII markers were integrated into the framework map composed of RFLP markers using software package MAPMAKER/Exp version 3.0b [67]. Recombination fractions were converted to centimorgans with the Kosambi mapping function [68].

\section{SNP identification, synteny study and cluster analysis}

Primer pairs which produced a locus-specific amplicon were used amplify template DNA from 27 wheat cultivars, using the appropriate PCR profiles described above. The PCR products were purified with the MinElute $^{\mathrm{Tw}}$ UF PCR purification kit (QIAGEN, Hilden Germany) following the manufacturer's instructions, and subjected to sequencing from both ends. SNPs were identified by Sequencher v4.06 software (Gene Codes
Cooperation, Ann Arbor, MI, USA). Position of the various SNPs shown in Additional file 3. Sequence alignment and phylogeny construction were performed using the MegAlign module of DNASTAR Lasergene ${ }^{\circ}$ v8.0. software. The resulting sequence alignments and phylogenetic trees are shown in Additional files 2, 3, 4, 5 and Figure 4. Phylogenetic trees were subjected to bootstrap analysis, based on 10,000 replicates.

\section{RNA isolation, CDNA synthesis and qRT-PCR}

Total RNA was extracted from cv. 'Prinz' seedlings and developing caryopses at 4, 8 and 12 days after anthesis, and from seedlings of cv. 'Chinese Spring', einkorn, goatgrass and T.durum using the TRIzol reagent (Invitrogen $\mathrm{GmbH}$, Karlsruhe, Germany) and RNAeasy columns (Qiagen, Hilden, Germany), as prescribed in the manufacturers' protocols, followed by in-column DNAse digestion. RNA concentration was measured using a NanoDrop photometer (Peqlab), following the manufacturer's instructions. A $2 \mu \mathrm{g}$ sample of RNA was used as template for cDNA synthesis, using the SuperScript ${ }^{\text {tw } I I I}$ kit (Invitrogen $\mathrm{GmbH}$ ), according to the manufacturer's instructions. cDNA yield was tested by quantitative PCR employing a serine/threonine protein phosphatase gene $(\operatorname{TaPP} 2 A)$ as reference. The cDNA was diluted to so that the concentration of all samples lay between \pm 1 $\mathrm{C}_{\mathrm{T}}$. A qRT-PCR assay of the A and D genome SPSII homoeologue targeted exonic regions, following recommended guidelines [69], while the B genome homoeologue targeted the unspliced intron. PCRs were performed in optical 384-well plates using the ABI PRISM ${ }^{\circ} 7900$ HT Sequence Detection System (Applied Biosystems, Foster City, CA, USA) and $\mathrm{SYBR}^{\circ}$ Green to monitor dsDNA synthesis. Each $10 \mu \mathrm{l}$ reaction contained $5 \mu \mathrm{l}$ $2 \times$ Power SYBR ${ }^{\circ}$ Green Master mix reagent (Applied Biosystems), $1 \mu \mathrm{lDNA}$ and $200 \mathrm{~nm}$ of each homoeologue-specific primer. The PCR profile was $50^{\circ} \mathrm{C} / 2 \mathrm{~min}$ and $95^{\circ} \mathrm{C} / 10 \mathrm{~min}$, followed by 45 cycles of $95^{\circ} \mathrm{C} / 15 \mathrm{~s}$, $60^{\circ} \mathrm{C} / 60 \mathrm{~s}$. Melting curves were recorded after cycle 45 by heating from $60^{\circ} \mathrm{C}$ to $95^{\circ} \mathrm{C}$ at $1.9^{\circ} \mathrm{C} \mathrm{min}{ }^{-1}$. Data were analysed using SDS2.2.1 software (Applied Biosystems). To generate a baseline-subtracted plot of the logarithmic increase in fluorescence signal $\left(\Delta R_{n}\right)$ versus cycle number, the baseline data were collected between cycles 3 and 15. To obtain $C_{T}$ values, the amplification plots were analysed at an $R_{n}$ threshold of 0.2. To compare data from different cDNA samples, the SPSII $\mathrm{C}_{\mathrm{T}}$ values were normalized against the expression of TaPP2A. PCR efficiency (E) was estimated from the exponential phase of each amplification, following [70]. Since these lay between 1.8 and 2.0 for all samples, the expression level was calculated as $2^{-\Delta C T}$, where $\Delta C_{T}$ represented the difference between the $\mathrm{C}_{\mathrm{T}}$ of the SPSSII homoeologue and that of $T a P P 2 A$. 


\section{Additional material}

\section{Additional file 1: Intron-exon lengths of SPSII gene family determined in 10 different plant genomes.}

Additional file 2: Sequence alignment of SPSII gene studied in all 10 genomes using MegAlign (ClustalW, slow/accurate). Boxes represented residues different from the consensus. TA(AA): Triticum aestivum $A$ genome, $T A(B B)$ : Triticum aestivum $B$ genome, $T A(D D)$ : Triticum aestivum D genome, TU: Triticum urartu, TS: Triticum speltoides, AT: Aegilops tauschii, HV: Hordeum vulgare, OS: Oryza sativa, SB: Sorghum bicolor, BD: Brachypodium distachyon.

Additional file 3: Sequence alignment of SPSII gene region containing six exons and six introns (intron 7 to exon 13) studied in nine genomes (without Triticum aestivum $D$ genome). TA(AA): Triticum aestivum-A genome, TA(BB): Triticum aestivum-B genome, AT: Aegilops tauschii, HV: Hordeum vulgare, TU: Triticum urartu, TS: Triticum speltoides, BD: Brachypodium distachyon, SB: Sorghum bicolor, OS: Oryza sativa. Sequences from $5^{\prime}$ UTR and $3^{\prime}$ end are not shown due to unavailbilty of all sequeneces in some cases. Positions with SNP represented by grey boxes. Sequence in red font represented homoeologue-specific primers with $3^{\prime}$ end SNP. Sequence in red font with underline represented overlapping forward and reverse homoeologue-specific primers with $3^{\prime}$ end SNP. Unspliced intron in TA (BB) sequence is shown by bold italic font. TA(AA): Triticum aestivum A genome, TA(BB): Triticum aestivum B genome, TU: Triticum urartu, TS: Triticum speltoides, AT: Aegilops tauschii, HV: Hordeum vulgare, OS: Oryza sativa, SB: Sorghum bicolor, BD: Brachypodium distachyon.

Additional file 5: Sequence alignment of six introns (intron 7-12) of SPSII gene that could be studied in nine genomes (without Triticum aestivum D genome) using MegAlign (ClustalW, slow/accurate). Boxes represented residues different from the consensus. TA(AA): Triticum aestivum A genome, TA(BB): Triticum aestivum B genome, TU: Triticum urartu, TS: Triticum speltoides, AT: Aegilops tauschii, HV: Hordeum vulgare, OS: Oryza sativa, SB: Sorghum bicolor, BD: Brachypodium distachyon.

Additional file 6: Sequence similarity and divergence of SPSII gene based on sequence alignment of different regions (a) Sequence similarity and divergence of SPSII gene based on region studied in all ten genomes (including Triticum aestivum D genome). (b) Sequence similarity and divergence of SPSII gene based on six exons (exon 8-13) compared in nine genomes (without Triticum aestivum D genome). (c) Sequence similarity and divergence of SPSII gene based on six introns (intron 7-12) compared in nine genomes (without Triticum aestivum D genome). TA(AA): Triticum aestivum A genome, TA(BB): Triticum aestivum B genome, TU: Triticum urartu, TS: Triticum speltoides, AT: Aegilops tauschii, HV: Hordeum vulgare, OS: Oryza sativa, SB: Sorghum bicolor, BD: Brachypodium distachyon.

Additional file 4: Sequence alignment of six exons (exon 8-13) of SPSII gene studied in nine genomes (without Triticum aestivum D genome) using MegAlign (ClustalW, slow/accurate). Boxes represented residues different from the consensus. TA(AA): Triticum aestivum A genome, TA(BB): Triticum aestivum B genome, TU: Triticum urartu, TS: Triticum speltoides, AT: Aegilops tauschii, HV: Hordeum vulgare, OS: Oryza sativa, SB: Sorghum bicolor, BD: Brachypodium distachyon.

\section{Acknowledgements}

The financial assistance received from the Alexander von Humboldt foundation for carrying out this study is gratefully acknowledged. The research work was carried under Humboldt Research Fellowship awarded to Shailendra Sharma. Authors also thanks to Dr. Christof Pietsch for PhredPhrap-Consed analysis.

\section{Author details}

${ }^{1}$ Leibniz Institute of Plant Genetics and Crop Plant Research (IPK), Corrensstr. 3, D-06466 Gatersleben, Germany. ${ }^{2}$ Sardar Vallabh Bhai Patel University of Agriculture and Technology, Modipuram, Meerut, Uttar Pradesh 250110, India. ${ }^{3}$ Iwate Biotechnology Research Center, Narita 22-174-4, Kitakami, Iwate
024-0003, Japan. ${ }^{4}$ Plant Breeding Institute, Christian-Albrechts University of Kiel, Olshausenstrasse 40, 24098 Kiel Germany. ${ }^{5}$ Department of Agronomy and Plant Breeding, College of Agriculture, Isfahan University of Technology, 841568311, Isfahan, Iran. ${ }^{6}$ Department of Plant Pathology, Throckmorton Plant Sciences Center, Kansas State University, Manhattan, KS 66506, USA.

\section{Authors' contributions}

SS carried out the molecular genetic studies, sequence alignment, phylogenetic analysis, splice alignment and primer designing. He conceived the study, participated in its design and drafted the manuscript. NS performed gene expression analysis and drafted part of the manuscript. VTH and CS contributed to CDNA synthesis and qRT-PCR analysis using homoeologue-specific primers. SS and ZNK helped in carrying out some genetic experiments. EA and SKS provided the $3 \mathrm{~A}$ specific sequence information. MSR coordinated the study, contributed to its conception and design, to interpretation of data and to revising the manuscript critically. Al authors read and approved the final manuscript.

Received: 5 February 2010 Accepted: 30 June 2010 Published: 30 June 2010

\section{References}

1. Lunn JE, Furbank RT: Sucrose biosynthesis in C4 plants. New Phytol 1999, 143:221-237.

2. Lunn JE, MacRae E: New complexities in the synthesis of sucrose. Curr Opin Plant Biol 2003, 6:208-214.

3. Strand A, Foyer CH, Gustafsson P, Gardestrom P, Hurry V: Altering flux through the sucrose biosynthesis pathway in transgenic Arabidopsis thaliana modifies photosynthetic acclimation at low temperatures and the development of freezing tolerance. Plant Cell Environ 2003, 26:523-535.

4. $\quad$ Yang J, Zhang J, Wang Z, Zhu Q: Activities of starch hydrolytic enzymes and sucrose-phosphate synthase in the stems of rice subjected to water stress during grain filling. J Exp Bot 2001, 52:2169-2179.

5. Castleden CK, Aoki N, Gillespie VJ, MacRae EA, Quick WP, Buchner P, Foyer CH, Furbank RT, Lunn JE: Evolution and function of the sucrosephosphate synthase gene families in wheat and other grasses. Plant Physiol 2004, 135:1753-1764.

6. Zhu YJ, Komor $\mathrm{E}$, Moore PH: Sucrose accumulation in the sugarcane stem is regulated by the difference between the activities of soluble acid invertase and sucrose phosphate synthase. Plant Physiol 1997, 115:609-616.

7. Grof CPL, Albertson PL, Bursle J, Perroux JM, Bonnett GD, Manners JM: Sucrose-phosphate synthase, a biochemical marker of high sucrose accumulation in sugarcane. Crop Sci 2007, 47:1530-1539.

8. Mc Intyre CL, Jackson M, Cordeiro GM, Amouyal O, Hermann S, Aitken KS, Eliott F, Henry RJ, Casu RE, Bonnett GD: The identification and characterisation of alleles of sucrose phosphate synthase gene family III in sugarcane. Mol Breed 2006, 18:39-50.

9. Causse M, Rocher JP, Henry AM, Charcosset A, Prioul JL, de Vienne D: Genetic dissection of the relationship between carbon metabolism and early growth in maize, with emphasis on key-enzyme loci. Mol Breed 1995, 1:259-272.

10. Causse M, Rocher JP, Pelleschi S, Barriere Y, de Vienne D, Prioul JL: Sucrosephosphate synthase: an enzyme with heterotic activity correlated with maize growth. Crop Sci 1995, 35:995-1001.

11. Sarquis Jl, Gonzalez H, Sánchez de Jimenez E, Dunlap JR: Physiological traits associated with mass selection for improved yield in a maize population. Field Crops Res 1998, 56:239-246.

12. Prioul JL, Pelleschi S, Séne $M$, Thévenot $C$, Causse $M$, de Vienne D, Leonardi A: From QTLs for enzyme activity to candidate genes in maize. J Exp Bot 1999, 50:1281-1288.

13. Bertin P, Gallais A: Genetic variation for nitrogen use efficiency in a set of recombinant inbred lines. II-QTL detection and coincidence. Maydica 2001, 46:53-68

14. Ishimaru K, Ono K, Kashiwagi $\mathrm{T}$ : Identification of a new gene controlling plant height in rice using the candidate-gene approach. Planta 2003, 218:388-395

15. Coleman HD, Beamish L, Reid A, Park JY, Mansfield SD: Altered sucrose metabolism impacts plant biomass production and flower development. Transgenic Res 2009, DOI 10.1007/s11248009-9309-5.. 
16. Park JY, Canam T, Kang KY, Ellis DD, Mansfield SD: Over-expression of an arabidopsis family A sucrose phosphate synthase (SPS) gene alters plant growth and fibre development. Transgenic Res 2008, 17:181-192.

17. Ishimaru K, Naoki H, Takayuki K, Yuka M, Kkiyoshi N, Kiyomi O, Ryu O: Overexpression of a Maize SPS Gene Improves Yield Characters of Potato under Field Conditions. Plant Prod Sci 2008, 11:104-107.

18. Worrell AC, Bruneau JM, Summerfelt K, Boersig M, Voelker TA: Expression of a maize sucrose phosphate synthase in tomato alters leaf carbohydrate partitioning. Plant Cell 1991, 3:1121-1130.

19. Lunn JE: Sucrose-phosphatase gene families in plants. Gene 2003, 303:187-196.

20. Suzuki T, Masaoka K, Nishi M, Nakamura K, Ishiguro S: Identification of kaonashi mutants showing abnormal pollen exine structure in Arabidopsis thaliana. Plant Cell Physiol 2008, 49:1465-1477.

21. Gale MD, Devos KM: Comparative genetics in the grasses. Proc Natl Acad Sci USA 1998, 95:1971-1974.

22. Blake NK, Sherman JD, Dvorak J, Talbert LE: Genome-specific primer sets for starch biosynthesis genes in wheat. Theor App/ Genet 2004, 109:1295-1302.

23. Caldwell KS, Dvorak J, Lagudah ES, Akhunov E, Luo MC, Wolters P, Powell W: Sequence polymorphism in polyploid wheat and their Dgenome diploid ancestor. Genetics 2004, 167:941-947.

24. Ravel C, Nagy IJ, Pierre M, Sourdille P, Mireille D, Balfourier F, Caroline P, Sandra G, Praud S, Charmet G: Single nucleotide polymorphism, genetic mapping, and expression of genes coding for the DOF wheat prolaminbox binding factor. Funct Integr Genomics 2006:310-321.

25. Haudry A, Cenci A, Ravel C, Bataillon T, Brunel D, Poncet C, Hochu I, Poirier S, Santoni S, Glemin S, David J: Grinding up wheat: a massive loss of nucleotide diversity since domestication. Mol Biol Evol 2007, 24:1506-1517

26. Khlestkina EK, Röder MS, Salina EA: Relationship between homoeologous regulatory and structural genes in allopolyploid genome-A case study in bread wheat. BMC Plant Biol 2008, 8:88.

27. Huang $X Q$, Röder MS: Development of SNP assays for genotyping the puroindoline $\mathrm{b}$ gene for grain hardness in wheat using pyrosequencing. J Agric Food Chem 2005, 53:2070-2075.

28. Whitt SR, Wilson LM, Tenaillon MI, Gaut BS, Buckler ES: Genetic diversity and selection in the maize starch pathway. Proc Natl Acad Sci USA 2002, 99:12959-12962.

29. Ravel C, Praud S, Murigneux A, Canaguier A, Sapet F, Samson D Balfourier F, Dufour P, Chalhoub B, Brunel D, Beckert M, Charmet G: Singlenucleotide polymorphism frequency in a set of selected lines of bread wheat (Triticum aestivum L.). Genome 2006, 49:1131-1139.

30. Somers DJ, Kirkpatrick R, Moniwa M, Walsh A: Mining single-nucleotide polymorphisms from hexaploid wheat ESTs. Genome 2003, 46:431-7.

31. Bryan GJ, Stephenson P, Collins A, Kirby J, Smith JB, Gale MD: Low levels of DNA sequence variation among adapted genotypes of hexaploid wheat. Theor Appl Genet 1999, 99:192-198.

32. Coleman CE, Clore AM, Ranch JP, Higgins R, Lopes MA, Larkins BA: Expression of a mutant a-zein creates the floury2 phenotype in transgenic maize. Proc Natl Acad Sci USA 1997, 94:7094-7097.

33. Aukerman MJ, Schmidt RJ, Burr B, Burr FA: An arginine to lysine substitution in the bZIP domain of an opaque-Z mutant in maize abolishes specific DNA binding. Genes Dev 1991, 5:310-320.

34. Haga H, Yamada R, Ohnishi Y, Nakamura Y, Tanaka T: Gene based SNP discovery as part of the Japanese Millenium Genome Project: identification of 190,562 genetic variations in the human genome. J Hum Genet 2002, 47:605-610.

35. Nomura T, Ishihara A, Yanagita RC, Endo TR, Iwamura $H$ : Three genomes differentially contribute to the biosynthesis of benzoxazinones in hexaploid wheat. Proc Natl Acad Sci USA 2005, 102:16490-16495.

36. Kurata N, Moore G, Nagamura Y, Foote T, Yano M, Minobe Y, Gale M: Conservation of genome structure between rice and wheat. Nat Biotech 1994, 12:276-278.

37. Devos KM, Gale MD: Genome relationships: the grass model in current research. Plant Cell 2000, 12:637-646.

38. Munkvold JD, Greene RA, Bermudez-Kandianis CE, La Rota CM, Edwards H, Sorrells SF, Dake T, Benscher D, Kantety R, Linkiewicz AM, Dubcovsky J, Akhunov ED, Dvorák J, Miftahudin, Gustafson JP, Pathan MS, Nguyen HT, Matthews DE, Chao S, Lazo GR, Hummel DD, Anderson OD, Anderson JA, Gonzalez-Hernandez JL, Peng JH, Lapitan N, Qi LL, Echalier B, Gill BS,
Hossain KG, Kalavacharla V, Kianian SF, Sandhu D, Erayman M, Gill KS, McGuire PE, Qualset CO, Sorrells ME: Group 3 chromosome bin maps of wheat and their relationship to rice chromosome 1. Genetics 2004, 168:639-50.

39. Sorrells ME, La Rota M, Bermudez-Kandianis CE, Greene RA, Kantety R, Munkvold JD, Miftahudin, Mahmoud A, Ma X, Gustafson PJ, Qi LL, Echalier B, Gill BS, Matthews DE, Lazo GR, Chao S, Anderson OD, Edwards H, Linkiewicz AM, Dubcovsky J, Akhunov ED, Dvorak J, Zhang D, Nguyen HT, Peng J, Lapitan NL, Gonzalez-Hernandez JL, Anderson JA, Hossain K, Kalavacharla V, Kianian SF, Choi DW, Close TJ, Dilbirligi M, Gill KS, Steber C, Walker-Simmons MK, McGuire PE, Qualset CO: Comparative DNA sequence analysis of wheat and rice genomes. Genome Res 2003, 13:1818-1827.

40. Li W, Gill BS: The colinearity of the Sh2/A1 orthologous region in rice, Sorghum and maize is interrupted and accompanied by genome expansion in the Triticeae. Genetics 2002, 160:1153-1162.

41. Isidore E, Scherrer B, Chalhoub B, Feuillet C, Keller B: Ancient haplotypes resulting from extensive molecular rearrangements in the wheat $A$ genome have been maintained in species of three different ploidy levels. Genome Res 2005, 15:526-536.

42. Li Z, Huang B, Rampling L, Wang J, Yu J, Morell M, Rahman S: Detailed comparison between the wheat chromosome group 7 short arms and the rice chromosome arms $6 \mathrm{~S}$ and $8 \mathrm{~L}$ with special reference to genes involved in starch biosynthesis. Funct Integr Genomics 2004, 4:231-240.

43. Paux E, Sourdille $P$, Salse J, Saintenac C, Choulet F, Leroy P, Korol A, Michalak M, Kianian S, Spielmeyer W, Lagudah E, Somers D, Kilian A, Alaux M, Vautrin S, Bergès H, Eversole K, Appels R, Safar J, Simkova H, Dolezel J, Bernard M, Feuillet C: A physical map of the 1-gigabase bread wheat chromosome 3B. Science 2008, 322:101-104.

44. Choulet F, Paux E, Salse J, Leroy P, Ghislaine M, Sylvie S, Valerie B, Feullet C: Sequencing, annotation and charcterization of $17 \mathrm{MB}$ of chromosome $3 \mathrm{~B}$ contigs provide novel insights into the wheat genome organization and evolution [abstract]. 19th International Triticae Mapping Initiative-3rd COST Tritigen 2009 Clermont-Ferrand, France 2009, 58.

45. Paterson AH, Bowers JE, Chapman BA: Ancient polyploidization predating divergence of the cereals, and its consequences for comparative genomics. Proc Natl Acad Sci USA 2004, 101:9903-9908.

46. Lu HJ, Faris JD: Macro- and micro-colinearity between the genomic region of wheat chromosome $5 B$ containing the Tsn 1 gene and the rice genome. Funct Int Genomics 2006, 6:90-103.

47. Singh NK, Dalal V, Batra K, Singh BK, Chitra G, Singh A, Ghazi IA, Yadav M, Pandit A, Dixit R, Singh PK, Singh H, Koundal KR, Gaikwad K, Mohapatra T, Sharma TR: Single-copy genes define a conserved order between rice and wheat for understanding differences caused by duplication, deletion, and transposition of genes. Funct Integr Genomics 2007, 7:17-35.

48. Feldman M, Liu B, Segal G, Abbo S, Levy AA, Vega JM: Rapid elimination of low-copy DNA sequences in polyploidy wheat: A possible mechanism for differentiation of homoeologous chromosomes. Genetics 1997, 147:1381-1387

49. Chalupska D, Lee HY, Faris JD, Evrard A, Chalhoub B, Haselkorn R, Gornicki P: Acc homoeoloci and the evolution of wheat genomes. Proc Natl Acad Sci USA 2008, 105:9691-9696.

50. Dvorak J, Zhang HB: Variation in repeated nucleotide sequences sheds light on the origin of the wheat B and G genomes. Proc Natl Acad Sci USA 1990, 87:9640-9644.

51. Vogel JP, Gu YQ, Twigg P, Lazo GR, Laudencia-Chingcuanco D, Hayden DM, Donze TJ, Vivian LA, Stamova B, Coleman-Derr D: EST sequencing and phylogenetic analysis of the model grass Brachypodium distachyon. Theor Appl Genet 2006, 113:186-195.

52. Bossolini E, Wicker T, Knobel PA, Keller B: Comparison of orthologous loci from small grass genomes Brachypodium and rice: implications for wheat genomics and grass genome annotation. Plant J 2007, 49:704-717.

53. Huo N, Lazo GR, Vogel JP, You FM, Ma Y, Hayden DM, Coleman-Derr D, Hill TA, Dvorak J, Anderson OD, Luo MC, Gu YQ: The nuclear genome of Brachypodium distachyon: analysis of BAC end sequences. Funct Integr Genomics 2007, 8:135-47.

54. Huo N, Vogel JP, Lazo GR, You FM, Ma Y, McMahon S, Dvorak J, Anderson OD, Luo MC, Gu YQ: Structural characterization of Brachypodium genome and its syntenic relationship with rice and wheat. Plant Mol Biol 2009, 70:47-61.

55. Kumar S, Mohan A, Balyan HS, Gupta PK: Orthology between genomes of Brachypodium, wheat and rice. BMC Res Notes 2009, 2:93. 
56. Plaschke J, Ganal MW, Röder MS: Detection of genetic diversity in closely related bread wheat using microsatellite markers. Theor Appl Genet 1995, 91:1001-1007.

57. Sturn A, Quackenbush J, Trajanoski Z: Genesis: cluster analysis ofmicroarray data. Bioinformatics 2002, 18:207-208.

58. Corpet F: Multiple sequence alignment with hierarchical clustering. Nucleic Acids Res 1988, 16:10881-10890.

59. Ewing B, Green P: Base-calling of automated sequencer traces using Phred. II. Error probabilities. Genome Res 1998, 8:186-194.

60. Gordon D, Abajian C, Green P: Consed: a graphical tool for sequence finishing. Genome Res 1998, 8:195-202.

61. Nickerson D, Tobe V, Taylor S: PolyPhred: automating the detection and genotyping of single nucleotide substitutions using fluorescence-based resequencing. Nucl Acids Res 1997, 25:2745-2751.

62. Altschul SF, Gish W, Miller W, Myers EW, Lipman DJ: Basic alignment search tool. J Mol Biol 1990, 215:403-410.

63. Altschul SF, Madden TL, Schäfer AA, Zhang JZ, Zhang Z, Miller W, Lipman DJ: Gapped BLAST and PSI-BLAST; a new generation of protein database search programs. Nucleic Acids Res 1997, 25:3389-3402.

64. Schlueter SD, Dong Q, Brendel V: GeneSeqer@PlantGDB: gene structure prediction in plant genomes. Nucleic Acids Res 2003, 31:3597-3600.

65. Rozen S, Skaletsky H: Primer3 on the www for general users and for biologist programmers. Bioinformatics Methods and Protocols: Methods in Molecular Biology Totowa, NJ: Humana Presskrawetz S, Misener S 2000, 365-386.

66. Van Deynze AE, Dubcovsky J, Gill KS, Nelson JC, Sorrells ME, Dvorak J, Gill BS, Lagudah ES, McCouch SR, Appels R: Molecular genetic maps for group 1 chromosomes of Triticeae species and their relation to chromosomes in rice and oat. Genome 1995, 38:45-59.

67. Lander ES, Green P, Abrahamson J, Barlow A, Daly MJ, Lincoln SE, Newberry L: Mapmaker: an interactive computer package for constructing primary genetic linkage maps of experimental and natural populations. Genomics 1987, 1:174-181.

68. Kosambi D: The calculation of map distances from recombination values. Ann Eugen 1944, 12:172-175.

69. Udvardi MK, Czechowski T, Scheible WR: Eleven Golden Rules of Quantitative RT-PCR. Plant Cell 2008, 20:1736-1737.

70. Ramakers C, Ruijter JM, Deprez RH, Moorman AF: Assumption-free analysis of quantitative real-time PCR data. Neurosci Lett 2003, 339:62-66.

doi:10.1186/1471-2229-10-134

Cite this article as: Sharma et al:: Delineating the structural, functional and evolutionary relationships of sucrose phosphate synthase gene family II in wheat and related grasses. BMC Plant Biology 2010 10:134.

\section{Submit your next manuscript to BioMed Central and take full advantage of:}

- Convenient online submission

- Thorough peer review

- No space constraints or color figure charges

- Immediate publication on acceptance

- Inclusion in PubMed, CAS, Scopus and Google Scholar

- Research which is freely available for redistribution

Submit your manuscript at www.biomedcentral.com/submit 